\title{
Estimation of Testosterone, Estradiol and some Markers in Sera of Iraqi Patients with Benign Prostatic Hyperplasia.
}

\author{
Fayhaa M.Khaleel* Ihsan A.AL-Shammri** \\ Nour AL-Huda G. Mohammed*
}

Received 20, September, 2012

Accepted 26, November, 2012

\begin{abstract}
:
Benign prostatic hyperplasia (BPH) is one of the most common disease and major cause of morbidity in elderly men which may lead to bladder outflow obstruction and lower urinary tract symptoms (LUTS). Although sex steroid hormones play fundamental roles in prostate growth, their clinical significance is not completely clear. In the present study we assessed whether serum hormones levels as markers of prostate disease. This study includes (40) patients with benign prostatic hypertrophy and (40) control group with age rang (41-79) and (42-71) years respectively. The following biochemical investigations have been studied: Testosterone, Estradiol $\left(\mathrm{E}_{2}\right)$, and Prostatic Specific Antigen (PSA) levels using ELISA method which correlated with the disease. Also body mass index (BMI), the prostate size by digital rectal examination (DRE), flow rate, and American Urology Association Symptoms Index (AUASI), of the patients which correlate hormones levels with age. The testosterone concentrations were significantly lower in patients with BPH than control group $(\mathrm{p} \leq 0.05)$, while the Estradiol and PSA concentrations were significantly higher in patients with $\mathrm{BPH}$ than control group $(\mathrm{p} \leq 0.05)$. The net result is a significant decrease in the T/E2 ratio allowing the imbalance between androgens and estrogen regulation of prostate growth to shift towards estrogen dominance. It has been proposed that increased estrogenic stimulation of the prostate in the aging male may lead to reactivation of growth and subsequent hyperplasia transformation
\end{abstract}

Key words: Benign Prostatic Hyperplasia (BPH), Testosterone (T), Estradiol $\left(\mathbf{E}_{2}\right)$, Prostatic Specific Antigen (PSA).

\section{Introduction:}

Benign prostatic hyperplasia $(\mathrm{BPH})$ is one of the most common disease and major cause of morbidity in elderly men which may lead to bladder outflow obstruction and lower urinary tract symptoms (LUTS) [1] . Although the pathogenesis of BPH is not well understood, it is probably linked to age-related changes in hormonal and other growth-regulatory factors that affect prostate growth and volume [2] .Though some males start to have prostatic hyperplasia after the fourth decade of life, it is not known why some develop it earlier and some males do not develop it at all. However, the overall incidence increases with age [3] and its prevalence reaches about $90 \%$ in men in their $80 \mathrm{~s}$, of whom only a proportion suffer from urinary symptoms. Medical and conservative treatments are used in management, but most patients eventually need surgery to get rid of the troublesome symptoms of prostatism. Until recently little has been known about the etiopathology and risk factors for this disease [4]. Studies on the

*Chemistry Dept. College of Science for women, Baghdad University. Baghdad, Iraq **AL_Yurmok Hospital, Urology Dept. Baghdad, Iraq. 
etiopathology and risk factors seem insufficient and are derived mainly from animal rather than human studies [3]. PSA is aglycoprotien that acts as a serine protease, of $33,000 \mathrm{MW}$. It contains $7 \%$ carbohydrate and is found almost exclusively in the epithelial cells of the prostate [5]. One possible biologic role of PSA is to lyse the clot of the ejaculate, however, it is yet not known why this clotting and lysing mechanisms are important to reproductive physiology [6]. Serum PSA is a powerful predictor of natural history of BPH. PSA values of more than $1.4 \mathrm{ng} / \mathrm{ml}$ reflect heightened risk of disease progression in middle aged and elderly men [7]. Testosterone and estrogens play important roles in prostate growth and function, and many scientists have hypothesized that the slow decline in serum testosterone levels or the decreasing ratio of testosterone to estrogen that begins in midlife are factors in $\mathrm{BPH}$ pathogenesis [2].

Androgens in males rise steadily followed by a slow decline in the mid30s [8]. After the 40s, the levels of androgens either remain constant or there is a slow decline with age. Though androgens, estrogens and their relative concentrations in the peripheral circulation are related to prostatic hyperplasia [9], it is not understood why prostatic hyperplasia develops in that period of life when serum androgens and probably estrogens in the peripheral circulation are relatively lower. Whether there are any change in androgens and other sex steroid concentrations in those who develop prostatic hyperplasia is also not clear [3]. It is important to find out whether there is any change in the sex steroid levels in prostatic hyperplasia. In addition, the age related changes in those hormones after 40 years of age need to be examined.
The present study aim to determine whether there is any change in the concentration of Testosterone, Estradiol in prostatic hyperplasia and also to determine to what extent these hormones change with age.

\section{Materials and Methods:}

For this study, $40 \mathrm{BPH}$ patients had been selected and 40 well-matched males without BPH as control group from the inpatient and outpatient of AL_Yurmok Hospital located in the city of Bagdad, Iraq during December 2011 to April 2012. Detalid medical and urological examinations were done on each subject before inclusion. Control samples were drawn from 40 men who had no more than 5 missing American urology association symptoms index (AUASI) values, no less than $11 \mathrm{Q}_{\max }$, no more than $33 \mathrm{~cm}^{3}$ of volume prostate, no surgical or medical treatment for $\mathrm{BPH}$, and no report of a physician diagnosis of $\mathrm{BPH}$. Participants completed a previously validated baseline questionnaire that assessed LUTS severity from questions similar to those in the AUASI, and a composite symptom index score was estimated. Participants also voided into a portable urometer to measure peak urinary flow rate. Also prostate volume was determined by digital rectal examination. The clinical and laboratory characteristics of the patients group and control groups are shown in (Table 1). Venous blood samples were collected from each subjects at the morning (9-12am), $5 \mathrm{ml}$ of blood were obtained by vein puncture using a $10 \mathrm{ml}$ disposable syringes. The blood sample was left for 15 minute to clot at room temperature, and then separated by centrifugation at (3000 rpm) for (5 min) then serum was collected. Serum was divided into three aliquots; in an Eppendroff tubes and stored in the freezer $(-20) C^{0}$ until laboratory analysis. Laboratory assays 
were done within 3monthes of collection. Serum samples were assayed for testosterone ( $\mathrm{T}$ )( Monobind Inc, USA Kit), estradiol ( $\left.E_{2}\right)$ ( DRG Instruments $\mathrm{GmbH}$, Germany Kit), prostatic specific antigen (PSA)( Diagnostic Automation, INC, USA Kit).Each Kit was supplied with instruction for hormone assay by ELISA (USA). Analysis of data was carried out using the available statistical package of SPSS-18 (Statistical Packages for Social
Sciences- version 18 "PASW" Statistics).

\section{Results:}

The present study have found a significant difference in the mean serum concentration of testosterone, $\mathrm{E}_{2}$, and PSA between BPH patients and control groups (Table 2), (Figure 1, 2, 3). Combining the patients group and control group, no significant correlation was found in testosterone, estradiol, with age. (Table 3), (Figure $4,5)$.

Table (1) Clinical profile of patients and control groups.

\begin{tabular}{|l|l|l|}
\hline Parameters & Patients group $(\mathbf{n = 4 0})$ & Control group $(\mathbf{n = 4 0})$ \\
\hline Age $($ year $)$ & $60.85 \pm 9.24$ & $51.02 \pm 3.42$ \\
\hline BMI $\left(\mathrm{kg} / \mathrm{m}^{2}\right)$ & $28.41 \pm 4.77$ & $28.03 \pm 4.14$ \\
\hline Prostatic symptom score & $16.05 \pm 6.26$ & $2.86 \pm 1.18$ \\
\hline Volumeof prostate $(\mathrm{cm} 3)$ & $49.55 \pm 8.63$ & $25.12 \pm 3.27$ \\
\hline Qmax & $7.65 \pm 1.59$ & $13.30 \pm 1.34$ \\
\hline
\end{tabular}

Values as mean \pm SD

Table (2) The mean \pm SD of Serum testosterone, estradiol, and prostatic specific antigen levels for BPH patients and control groups.

\begin{tabular}{|l|l|l|l|}
\hline Parameters & Patients group $(\mathbf{n}=\mathbf{4 0})$ & Control group $(\mathbf{n}=40)$ & P value \\
\hline Testosterone $(\mathrm{ng} / \mathrm{ml})$ & $2.89 \pm 1.89$ & $4.12 \pm 1.34$ & $0.002^{*}$ \\
\hline $\mathrm{E}_{2}(\mathrm{pg} / \mathrm{ml})$ & $45.83 \pm 38.13$ & $17.08 \pm 10.35$ & $0.0001^{*}$ \\
\hline $\mathrm{PSA}(\mathrm{ng} / \mathrm{ml})$ & $2.85 \pm 1.58$ & $1.02 \pm 0.62$ & $0.0001^{*}$ \\
\hline $\mathrm{T}_{\mathrm{E}} \mathrm{E}_{2}$ ratio & $0.123 \pm 0.172$ & $0.328 \pm 0.224$ & $0.0001^{*}$ \\
\hline
\end{tabular}

*significant at $\mathrm{p}<0.05$

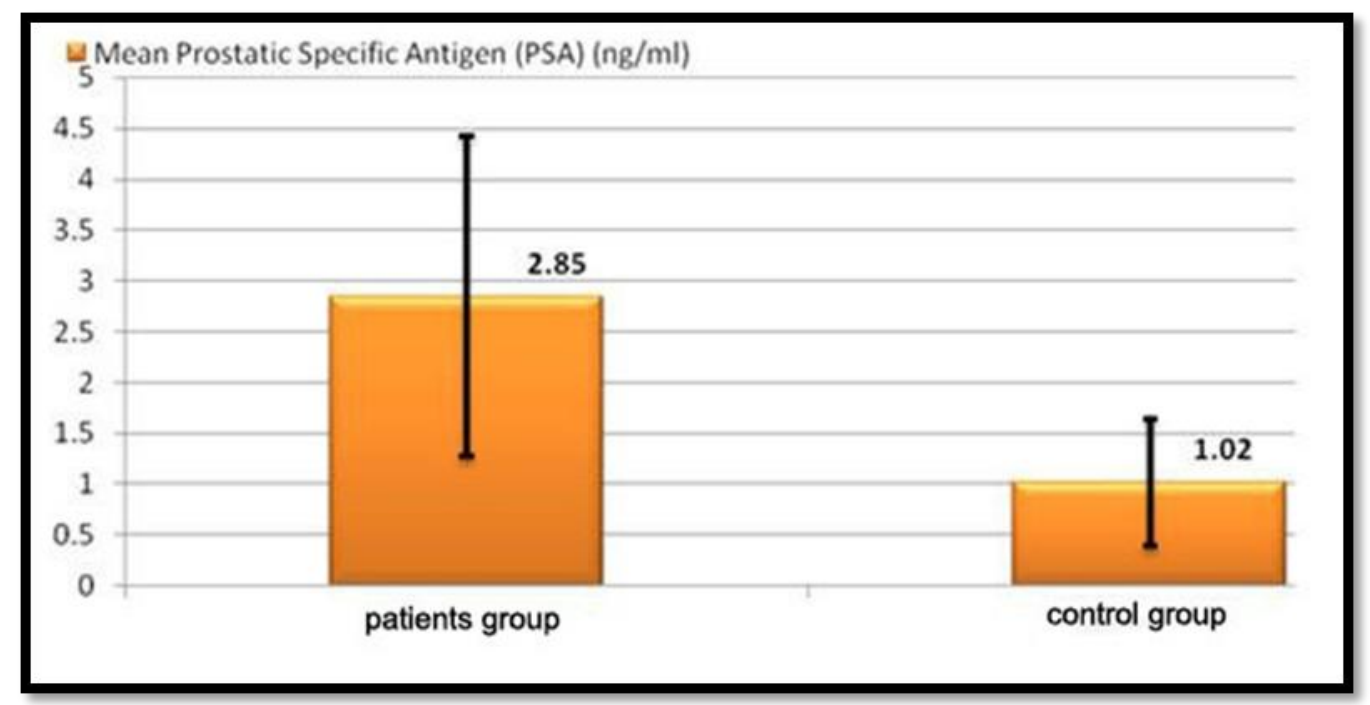

Fig. (1): The mean of serum PSA (ng/ml ) for BPH patients and control groups. 


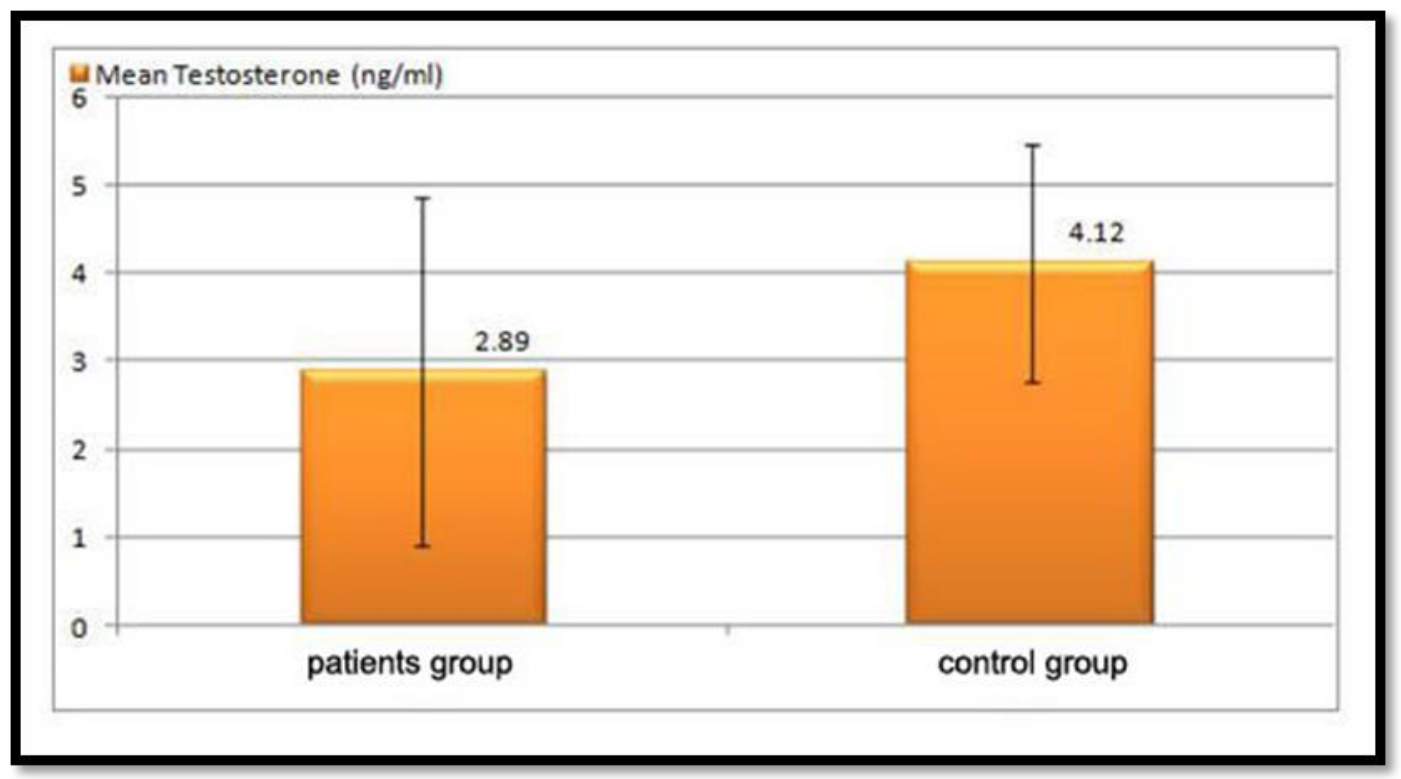

Fig.(2): The Mean of serum testosterone $(\mathrm{ng} / \mathrm{ml})$ for BPH patients and control groups .

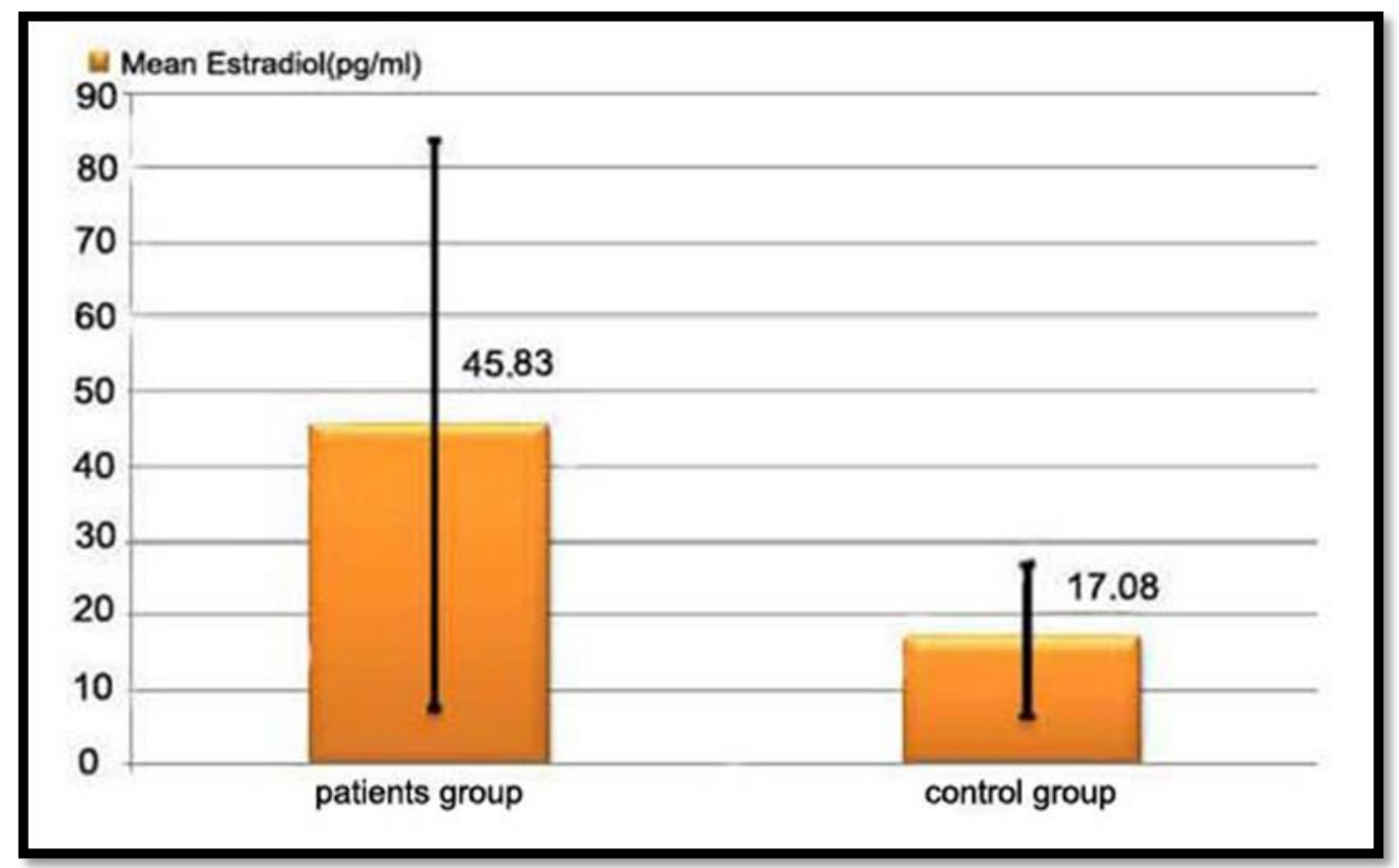

Fig.(3): The Mean of serum Estradiol $\left(\mathrm{E}_{2}\right)(\mathrm{pg} / \mathrm{ml})$ for $\mathrm{BPH}$ patients and control groups.

Table (3):- Correlations of testosterone, and estradiol with age.

\begin{tabular}{|l|l|l|}
\hline Parameters & Correlation coefficient & P value \\
\hline $\mathrm{T}(\mathrm{ng} / \mathrm{ml})$ & -0.084 & 0.605 \\
\hline $\mathrm{E}_{2}(\mathrm{pg} / \mathrm{ml})$ & -.087 & 0.595 \\
\hline PSA $(\mathrm{ng} / \mathrm{ml})$ & 0.304 & 0.057 \\
\hline
\end{tabular}




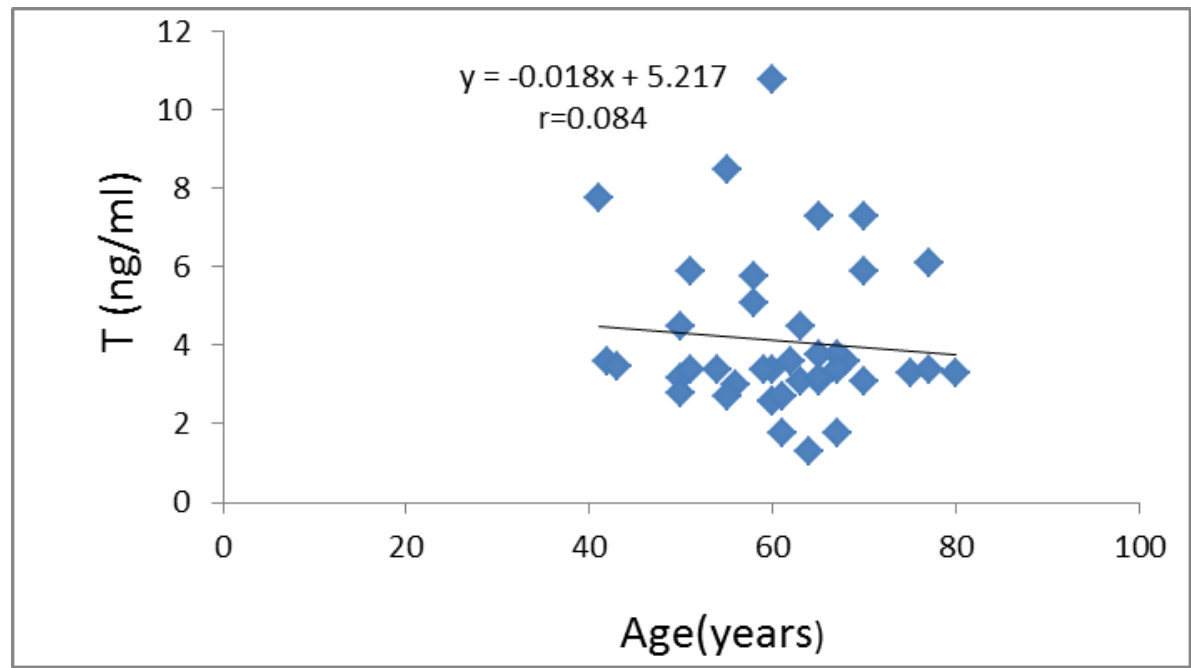

Fig.(4):- Correlation between Testosterone (T) levels and age in patients with BPH

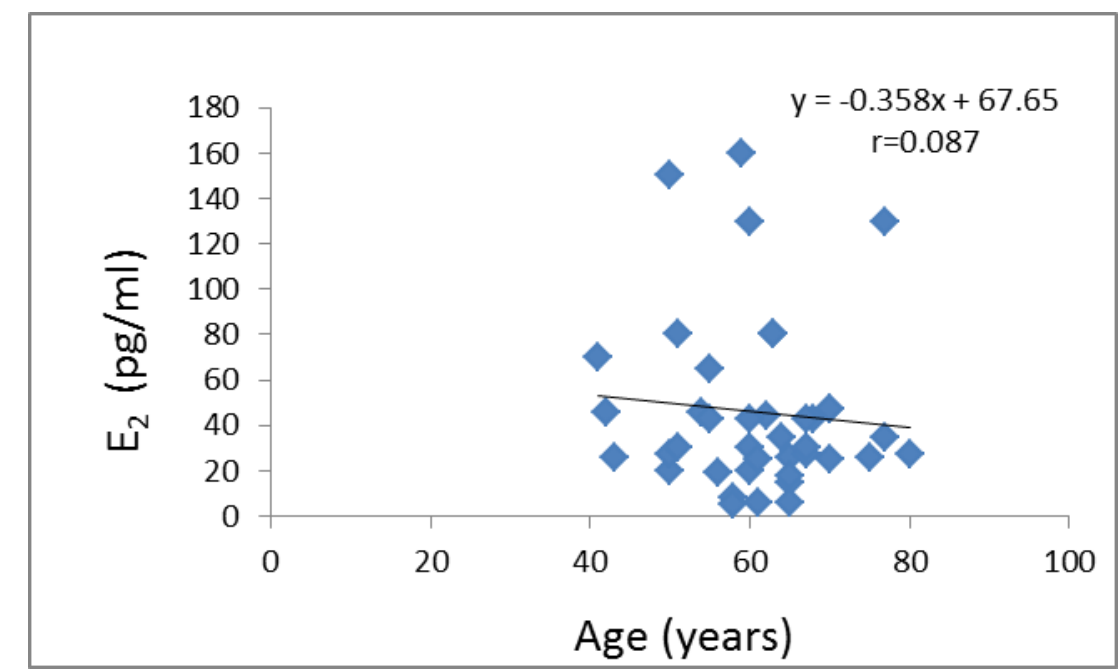

Fig.(5):- Correlation between Estradiol $\left(\mathrm{E}_{2}\right)$ levels and age in patients with $\mathrm{BPH}$.

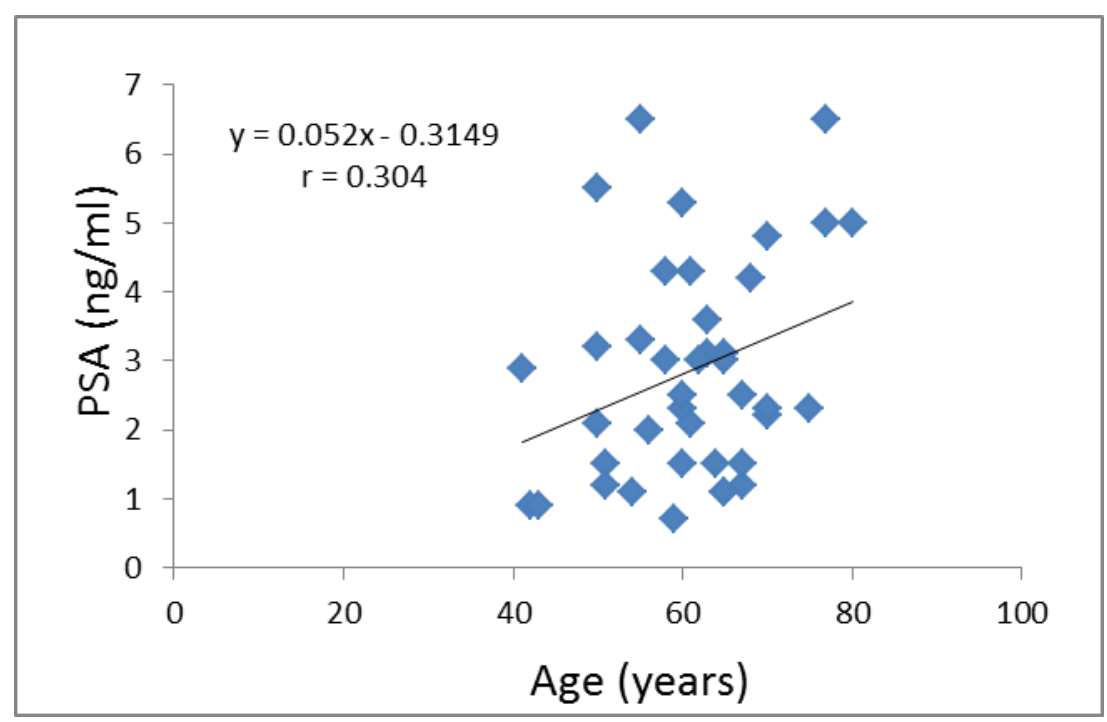

Fig.(6):- Correlation between Prostatic Specific Antigen(PSA) levels and age in patients with BPH. 


\section{Discussion:}

Serum PSA is primarily a tissuespecific marker. PSA is a valuable index of BPH disease risk. After prostate cancer is excluded PSA is a reasonable clinical surrogate marker for prostate volume [10]. Men with large prostate glands have high PSA and are at increased risk for BPH disease progression [11, 12]. Therefore, PSA is also a marker for BPH risk disease as shown in current study (table 2), (figure 1), (figure 6).

In the present study there have been found a significant association as shown in (table 2), (figure 2) in serum testosterone level in benign prostatic hyperplasia. These results agree with earlier studies where high serum testosterone levels were associated with lower BPH risk. Kristal et al. [2] reported the same results for androgens concentration as in current study. In fact, most of the recent studies found strong change in serum testosterone concentration in prostatic hyperplasia. Prehn [13] also reported that with low testosterone, the normal milieu might be varied enough to disrupt the normal growth and maintenance of prostatic tissue, while compensatory hyperplasia arises when the prostate atrophies might lead to cell mutations and consequent selection of androgensindependent aggressive prostate cell growth. Two studies have found that high testosterone was associated with reduce lower urinary tract symptoms [14]. Ansari MAJ et al. [3] reported that there was no significant change in serum levels of testosterone, estradiol, in clinical BPH as compared with agematched asymptomatic males with a normal-sized prostate. Meigs et al. and Gann et al. $[8,15]$ found no association between serum sex hormone levels and development of BPH. In the study by Marberger et al where clinical BPH was found to occur in elderly males with different baseline serum testosterone, ranging from low to high normal levels [16]. Estrogen action may be viewed in two different ways, the systemic endocrine effects via the pituitary that indirectly lower androgens levels and the direct local effects exerted via intra-prostatic estrogen receptors [17]. Estradiol-2, the major biologically active estrogen, is a metabolite of testosterone, and in adult men about $80 \%$ of it originates from aromatization of testosterone, especially in adipose tissue, while less than $20 \%$ of circulating estradiol is secreted by testis [17]. Current study found as shown in (table1), (figure 3), that estradiol was significantly associated with $\mathrm{BPH}[2, \quad 15]$. In contrast, Gann et al. [15] reported a positive association between estradiol and incident BPH surgery but only among men with low testosterone and only after control groupling for estrone, which suggests that the strong collinearity of estrone and estradiol may have yielded an unstable statistical model. Rohrmann et al. [18] reported a positive association of estradiol with lower urinary tract symptoms. The prostate expresses both estrogen receptor (b) (in epithelium, where it inhibits growth) and estrogen receptor (a) (in stroma, where it promotes growth). There is little evidence that estrogen receptor (a) has a role in BPH[20], and thus a growthinhibitory effect of estradiol could be consistent with reduced BPH risk[21,22]. It is also possible that a high estradiol level simply reflects a high testosterone level, because estradiol in older men is almost exclusively formed by aromatization of testosterone. Other studies [19-23] observed that abdominal obesity is a risk factor for $\mathrm{BPH}$, because abdominal obesity also increases estradiol levels.

A few studies reported an altered androgens-estrogen ratio in benign prostatic hyperplasia,[24,25] the 
present study found the same results in this study as show in (Table 2). The net result is a significant decrease in the T/E2 ratio allowing the imbalance between androgens and estrogen regulation of prostate growth to shift towards estrogen dominance. It has been proposed that increased estrogenic stimulation of the prostate in the aging male may lead to reactivation of growth and subsequent hyperplasia transformation [26]. Most studies support our findings as shown in (Table 3), (figure 4) of no change in serum $\mathrm{T}$ with age [3]; while few studies report a slow decline of andrsogens in aging males [27,28]. In contrast to those studies where an age related decline of androgens were reported [29, 30]. Despite a few studies indicating a significant association of estradiol with age [27, 31 ], the present study showed that no significant association between estradiol with age as show in (table 3), (figure 5). In summary, the serum levels of T and E2 in the present study were associated with clinical BPH as compared with age-matched asymptomatic males with a normal size of prostate. In addition, there is no significant age-related change in serum testosterone, E2 in the males without any systemic diseases.

\section{References :}

1. Tarcan, T. Ozdemir, I. Yazc, C. and Ilker Y. 2006. Are cigarette smoking, alcohol consumption and hypercholestrolmia risk factors for clinical benign prostatic hyperplasia. MMJ. 19(1); 21-26.

2. Kristal, A.R. Schenk, J.M. Song, Y. Schenk, J.M. Song, Y. Arnold, K.B. Neuhouser, M.L. Goodman, P.J. Lin, D.W. Stanczyk, F.Z. and Thompson. I.M. 2008. Serum steroid and sex hormone-binding globulin concentrations and the risk of incident benign prostatic hyperplasia: results from the Prostate Cancer Prevention Trial. Am. J. Epidemiol. 168(12): 14161424.

3. Ansari, M.A.J. Dilruba, B. and Fakhrul. I. 2008. Serum sex steroids, gonadtrophins and sex hormone-binding globulin in prostatic hyperplasia. Ann Saudi Med. 28(3);174-178.

4. Meigs, J.B. Mohr, B. Barry, M.J. Collins, M.M. and McKinla. J.B. 2001. Risk factors for clinical benign prostatic hyperplasia in a community based population of healthy aging men. J Clin Epidemiol. 54:935-944.

5. Rittenhouse, H.G. Finaly, J.A. Mikolajczyk, S.D. and Partin. A.W. 1998. Human kallikrein (hk2) and prostate-specific antigen (PSA): Tow closely related, but distinct, kallikreins in the prostate. Crit Revs Lab Sci. 35:275-368.

6. Lilja, H. 1995. A kallikrein like serum protease in prostatic fluid cleaves the predominant seminal vesicle protein. $\mathrm{J}$ Clin Invest. 78:1899-1903.

7. Catalona, W.J. Smith, D.S. Ratliff, T.L. Dodds, K.M. Coplen, D.E. Yuan, J.J. Petros, J.A. and Andriole. G.L. 1991. Measurement of prostate specific antigen in serum as ascreening test for prostate cancer. N Engl J Med. 324;1156-1161.

8. Stearns, E.L. Macdonell, J.A. Kauffman, B.J. Padua, R. Lucman, T.S. Winter, J.S. and Faiman .C. 1974. Decline of testicular function with age- hormonal and clinical correlates. Am J Med. 757:761.

9. Lynch Ah. 1998. Benign prostatic hyperplasia- from bench to bedside (editorial) J Urology. 159:1978.

10. Roehrborn, C.G. Boyle, P. Gould, A.L. and Waldstreicher. J. 1999. Serum prostate specific antigen as a predictor of prostate volume in men 
with benign prostatic hyperplasia. Urology. 53:581-589.

11. Roehrborn, C.G. Boyle, P. Bergner, D. Gray, T. Gittelman, M. Shown, T. Melman, A. Bracken, R.B. White, R.D. Taylor, A. Wang, D. and Waldstreicher. J. 1999. Serum prostate-specific antigen and prostate volume predict long-term changes in symptoms and flow rate: results of a four-year, randomized trial comparing finasteride versus placebo. Urology. 54: 662.

12. Roehrborn, C.G. McConnell, J.D. Lieber, M. Kaplan, S. Geller, J. Malek, G.H. Saltzman, B. Resnick, M. Cook, T.J. and Waldstreicher. J. 1999. Serum prostate-specific antigen concentration is a powerful predictor of acute urinary retention and need for surgery in men with clinical benign prostatic hyperplasia. Urology. 53: 473.

13. Prehn RT. 1999. On the prevention and therapy of prostate cancer by androgen administration. Cancer Res. 59:4161-4164.

14. Litman, H.J. Bhasin, S. O'Leary, M.P. Link, C.L. and McKinlay, J.B. 2007. An investigation of the relationship between sex-steroid levels and urological symptoms: results from the Boston Area Community Health Survey. BJU Int. ; 100(2):321-326.

15. Gann, P.H. Hennekens, C.H. Longcope, C. and Stampfer. M.J. 1995. A prospective study of plasma hormone levels, nonhormonal factors and development of benign prostatic hyperplasia. Prostate. 26(1):40-49.

16. Marberger, M. Roehrborn, C.G. Marks, 1.S. Wilson, T. and Rittmaster. R.S. 2006. Relationship among serum testosterone, sexual function and response to treatment in men receiving dutasteride for benign prostatic hyperplasia. J Clin Endocrinol Metab. 91:1323-1328.
17. Vermeulen, A. Raufman, J.M. Goemaeme, S. and Van Pottelberg. I. 2002. Estradiol in elderly men. Aging Male. 5:98-102.

18. Rohrmann, S. Nelson, W.G. Rifai, N. Kanarek, N. Basaria, S. Tsilidis, K.K. Smit, E. Giovannucci, E. and Platz. E.A. 2007. Serum sex steroid hormones and lower urinary tract symptoms in Third National Health and Nutrition Examination Survey (NHANES III). Urology. 69(4):708-713.

19. Platz, E.A. Kawachi, I. Rimm, E.B. Longcope, C. Stampfer, M.J. Willett, W.C. and Giovannucci. E. 1999. Plasma steroid hormones, surgery for benign prostatic hyperplasia, and severe lower urinary tract symptoms. Prostate Cancer Prostatic Diseases. 2(5/6):285-289.

20. Ellem, S.J. and Risbridger, G.P. 2007. Treating prostate cancer: a rationale for targeting local oestrogens. Nat Rev Cancer. 7(8): 621-627.

21. Kristal, A.R. Arnold, K.B. Schenk, J.M. Neuhouser, M.L. Weiss, N. and Goodman. P. 2007. Race/ethnicity, obesity, health related behaviors and the risk of symptomatic benign prostatic hyperplasia: results from the Prostate Cancer Prevention Trial. J Urology. 177(4):1395-1400.

22. Chokkalingam, A.P. Gao, Y.T. Deng, J. Stanczyk, F.Z. Sesterhenn, I.A. Mostofi, F.K. Fraumeni, J.F.Jr. and Hsing. A.W. 2002. Insulin-like growth factors and risk of benign prostatic hyperplasia. Prostate. 52(2):98-105.

23. Dahle, S.E. Chokkalingam, A.P. Gao, Y.T. Deng, J. Stanczyk, F.Z. and Hsing. A.W. 2002. Body size and serum levels of insulin and leptin in relation to the risk of benign prostatic hyperplasia. $\mathbf{J}$ Urology. 168(2):599-604. 
24. Grayhack, J.T. Kozlowski, J.M. and Lee Chung. 1998. The pathogenesis of benign prostatic hyperplasia: a proposed hypothesis and critical evaluation. J Urology. 160:2375-2380.

25. Weisher, H. and Kreig. M. 1997. Benign prostatic hyperplasia - the outcome of age-induced alteration of androgen estrogen balance? Urology; 36:3-9.

26. King, K.J. Nicholson, H.D. and Assinder. S.J. 2006. Effect of increasing ratio of estrogen: androgen on proliferation of normal and human prostate stromal and epithelial cells and the malignant cell line LNCaP. Prostate. 66:105114.

27. Ferrini, R.L. and Barrett-Connor. E. 1998. Sex hormones and age: A cross sectional study of testosterone and estradiol and their bioavailable fractions in community dwelling men. Am J Epidemiol. 147:750-754.
28. Harman, S.M. and Tsitouras. P.D. 1980. Reproductive hormones in aging men-Measurement of sex steroids, basal leutinizing hormone, and leydig cell response to human chorionic gondotrphins.J Cli Endocrinol Metab. 51:35-40.

29. Swerdloff, R.S. and Wang. C. 1993. Androgen deficiency and aging in men. West J Med. 159:579585.

30. Kaufman, J.M. and Vermeulen, A. 2005. The decline of androgen levels in elderly men and its clinical and therapeutic implications. Endocr Rev. 26(6):833-876.

31. Orwoll, E. Lambert, L.C. Marshal, L.M. Phipps, K. Blank, J. Connor, E.B. Cauley, J. Ensrud, K. and Cummings. S. 2006. Testosterone and estradiol among older men. J Clin Endocrinol Metab. 91:12231225 . 


\section{تقدير التيستوستيرون والاسترادايول وبعض الدلائل في مصل المرضى العراقيين المصابين بتضخم البروستات الحميد}

نور الهبى غازي محمد*

|حسان علمي الشدريث*

فيحاء مقد/د خليل

*ق*سم الكيمياء /كلية العلوم للبنات

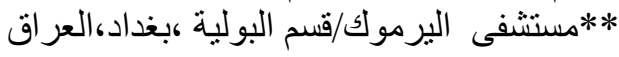

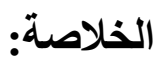

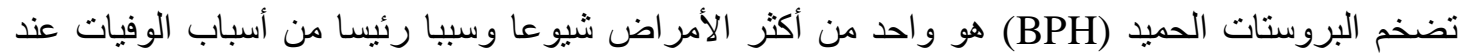

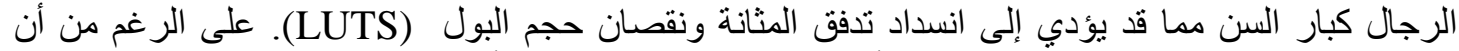

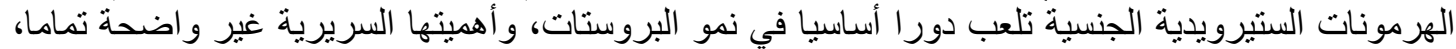

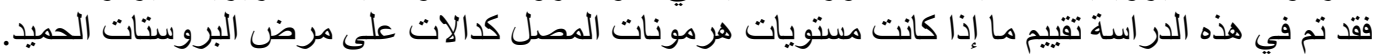

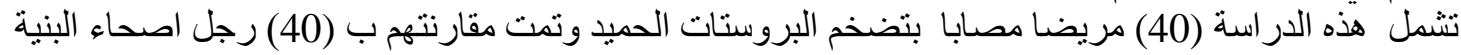

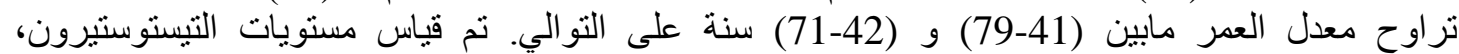

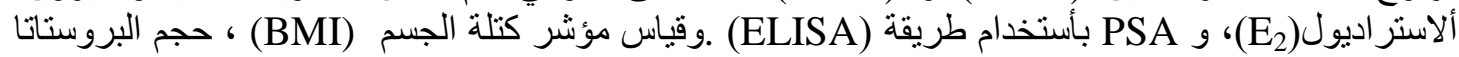

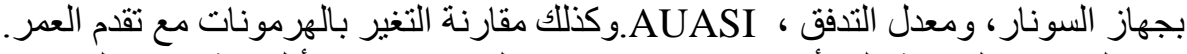

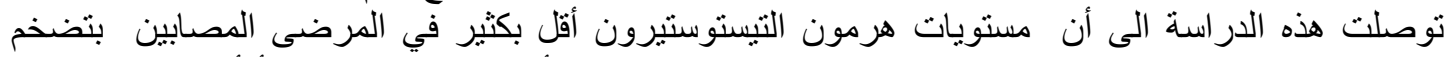

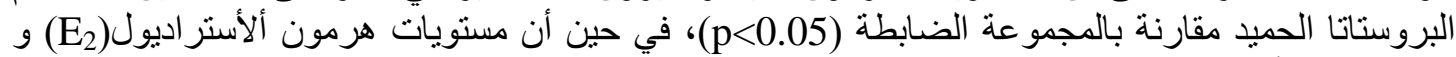
كانت أعلى (pSA

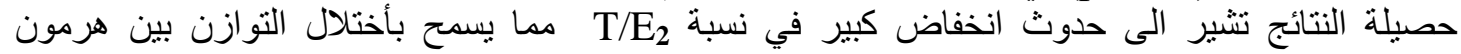

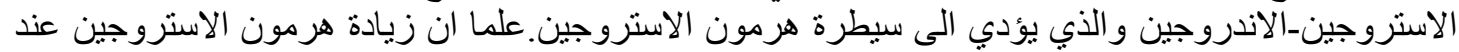

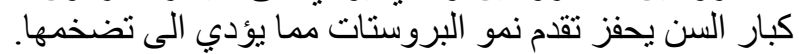

